\title{
Effects of early corticosteroid use in patients with severe coronavirus disease 2019
}

Jong Hoon Hyun', Moo Hyun Kim', Yujin Sohn', Yunsuk Cho', Yae Jee Baek1, Jung Ho Kim¹, Jin Young Ahn, Jun Yong Choi ${ }^{1}$, Joon Sup Yeom', Mi Young Ahn², Eun Jin Kim, Ji-Hyeon Baek, Young Keun Kim5, Heun $\mathrm{Choi}^{6}$ and Su Jin Jeong ${ }^{1 *}$ (D)

\begin{abstract}
Background: Coronavirus disease 2019 (COVID-19) is associated with acute respiratory distress syndrome, and corticosteroids have been considered as possible therapeutic agents for this disease. However, there is limited literature on the appropriate timing of corticosteroid administration to obtain the best possible patient outcomes.

Methods: This was a retrospective cohort study including patients with severe COVID-19 who received corticosteroid treatment from March 2 to June 30, 2020 in seven tertiary hospitals in South Korea. We analyzed the patient demographics, characteristics, and clinical outcomes according to the timing of steroid use. Twenty-two patients with severe COVID-19 were enrolled, and they were all treated with corticosteroids.

Results: Of the 22 patients who received corticosteroids, 12 patients (55\%) were treated within 10 days from diagnosis. There was no significant difference in the baseline characteristics. The initial $\mathrm{PaO}_{2} / \mathrm{FiO}_{2}$ ratio was 168.75 . The overall case fatality rate was $25 \%$. The mean time from diagnosis to steroid use was 4.08 days and the treatment duration was 14 days in the early use group, while those in the late use group were 12.80 days and 18.50 days, respectively. The $\mathrm{PaO}_{2} / \mathrm{FiO}_{2}$ ratio, C-reactive protein level, and cycle threshold value improved over time in both groups. In the early use group, the time from onset of symptoms to discharge ( 32.4 days vs. 60.0 days, $P=0.030$ ), time from diagnosis to discharge ( 27.8 days vs. 57.4 days, $P=0.024$ ), and hospital stay ( 26.0 days vs. 53.9 days, $P=0.033$ ) were shortened.

Conclusions: Among patients with severe COVID-19, early use of corticosteroids showed favorable clinical outcomes which were related to a reduction in the length of hospital stay.
\end{abstract}

Keywords: Coronavirus disease 2019, COVID-19, SARS-CoV-2, Pneumonia, Corticosteroid

\section{Background}

Coronavirus disease 2019 (COVID-19), a disease caused by severe acute respiratory syndrome coronavirus 2 (SARSCoV-2), was first reported in China in late 2019 [1]. It has affected almost 25 million people worldwide, and resulted in

\footnotetext{
* Correspondence: JSJ@yuhs.ac

'Department of Internal Medicine, Severance Hospital, Yonsei University College of Medicine, 50-1 Yonsei-ro Seodaemun-gu, Seoul 03722, South Korea

Full list of author information is available at the end of the article
}

the deaths of more than 850,000 as of August 31, 2020 [2]. The majority of infected patients are asymptomatic and show only mild symptoms; however, the remainder of patients experience a severe form of the disease. Elderly patients and patients with underlying diseases, such as diabetes mellitus, hypertension, and immunosuppressive disorders, have considerable morbidity and mortality when co-infected with COVID-19 [3, 4]. The overall fatality rate is approximately $0.4-2.0 \%$, but may be up to $50 \%$ in patients with lifethreatening illnesses [5], a finding which suggests that it is

(c) The Author(s). 2021 Open Access This article is licensed under a Creative Commons Attribution 4.0 International License, which permits use, sharing, adaptation, distribution and reproduction in any medium or format, as long as you give appropriate credit to the original author(s) and the source, provide a link to the Creative Commons licence, and indicate if changes were made. The images or other third party material in this article are included in the article's Creative Commons licence, unless indicated otherwise in a credit line to the material. If material is not included in the article's Creative Commons licence and your intended use is not permitted by statutory regulation or exceeds the permitted use, you will need to obtain permission directly from the copyright holder. To view a copy of this licence, visit http://creativecommons.org/licenses/by/4.0/ The Creative Commons Public Domain Dedication waiver (http://creativecommons.org/publicdomain/zero/1.0/) applies to the data made available in this article, unless otherwise stated in a credit line to the data. 
necessary to use different treatment approaches in these patients.

Severe COVID-19 is accompanied by inflammatory organ injury and causes acute respiratory distress syndrome, shock, or cardiac failure due to elevated levels of inflammatory cytokines and biomarkers. These include C-reactive protein (CRP), erythrocyte sedimentation rate (ESR), ferritin, and Ddimer $[6,7]$. Although the main pathophysiology of COVID19 is not completely understood, excessive inflammation is closely related to the development of pneumonia and rapid progression of the disease [6, 8]. Anti-inflammatory treatments, such as corticosteroids, are therefore, therapeutic options for severe COVID-19 [9].

Several potential therapeutics have been proposed in the early phase of the COVID-19 pandemic, such as chloroquine, hydroxychloroquine, lopinavir/ritonavir, azithromycin, intravenous immune globulin, and convalescent plasma transfusion; but corticosteroids and remdesivir have been known to improve clinical outcome so far $[10,11]$.. Corticosteroid, especially methylprednisolone, have been widely used in patients with severe COVID-19 cases in South Korea before the WHO and CDC made recommendations against using corticosteroid. Although some studies have shown that the usefulness of corticosteroid is limited [12-14], it has still become a potentially good therapeutic option as other studies, including the RECOVERY trial [11], have demonstrated beneficial effects of corticosteroid use [15-18]. The RECOVERY trial is a large-scale, prospective, well-designed study, which demonstrated that the use of dexamethasone reduces mortality in patients with severe COVID-19 [11]. Other types of corticosteroids, such as hydrocortisone [19], have also been demonstrated to improve clinical outcomes [20]. The use of corticosteroids could theoretically cause several side effects [21], but did not inhibit secondary bacterial infection or viral clearance [22, 23]. Strong evidence for dexamethasone use has been suggested from the RECOVERY trial. Because this trial has strong evidence for corticosteroid use, relatively fewer other studies were conducted. As a result, there is insufficient data to determine which types of corticosteroid (dexamethasone, hydrocortisone, methylprednisolone) are more beneficial [20], and the appropriate duration [24] and timing to start corticosteroid use still remain controversial.

This study aimed to analyze the results in groups with early and late use of corticosteroids to determine the right timing of corticosteroid use in patients with severe COVID-19.

\section{Methods}

\section{Study design and population}

This was a retrospective cohort study of patients with severe cases of COVID-19 who received corticosteroid treatment between March 2 and June 30, 2020 in seven tertiary hospitals in South Korea. The current study included patients aged $\geq 18$ years with laboratoryconfirmed SARS-CoV-2 infection who were admitted to the ICU. Patients with insufficient clinical data due to hospital transfers were excluded.

Electronic medical records were reviewed for baseline demographics, comorbidities, clinical characteristics, clinical status, laboratory findings, treatment, clinical course, and outcomes. Data were compared before steroid use, as well as 3, 7, and 14 days later.

This study was conducted in accordance with the guidelines of the Declaration of Helsinki and approved by the Institutional Review Boards of Severance Hospital (Seoul, South Korea). The requirement for informed consent was waived because of the retrospective nature of the study. All data was anonymized to keep the confidentiality of the patient's personal information during the entire research process including patient data collection, analysis and writing.

\section{Definition}

SARS-CoV-2 RNA was assessed by real-time reverse transcription polymerase chain reaction (RT-PCR) of nasopharyngeal swabs or sputum according to the World Health Organization interim guidance. RT-PCR assays for the $E, R d R p$, and $N$ genes were performed using the Allplex ${ }^{\mathrm{nx}}$ 2019-nCoV Assay (Seegene Inc., Seoul, South Korea). Positive RT-PCR results were defined as a cycle threshold $(\mathrm{Ct})$ value $\leq 40$. The severity was assessed by $\mathrm{PaO}_{2} / \mathrm{FiO}_{2}$ ratio and categorized into seven scores based on oxygen supplementation: no limit of activity, limit of activity but no $\mathrm{O}_{2}, \mathrm{O}_{2}$ with nasal prong, $\mathrm{O}_{2}$ with facial mask, high flow nasal cannula, noninvasive ventilation, and invasive ventilation.

The patients were divided into two groups by the time to corticosteroid use. Patients who were treated with corticosteroids within 10 days and after 10 days of confirmation were categorized as the early use group and the late use group, respectively.

CRP concentration was measured in serum using a nephelometric method (Beckman Coulter, Fullerton, CA, USA).

\section{Statistical analysis}

Continuous variables were examined for normality by Kolmogorov-Smirnov test. Continuous variables with normal distribution were shown as the mean \pm standard deviation (SD). Group comparisons were performed using independent two-sample t-test. Continuous nonnormal distribution variables were shown as the median interquartile range (3rd interquartile range-1st interquartile range), and Mann-Whitney $\mathrm{U}$ tests were used to compare the differences between groups. Categorical 
variables were shown as numbers (percentages). Chisquared tests and Fisher's exact test were used to compare categorical data in different groups. Laboratory findings were analyzed based on a linear mixed model using groups (early or late) and time (after corticosteroid administration) and an interaction between groups and time. Spearman's correlation coefficient was calculated to analyze correlation of variables. Statistical significance was set at $P<0.05$. All statistical analyses were performed using the Statistical Package for the Social Sciences version 25.0 (IBM Corporation, Armonk, NY, USA).

\section{Results}

During the study period, 22 patients who met the inclusion criteria were categorized into the early use group $(n=12)$ or the late use group $(n=10)$. The baseline demographics and characteristics of each group were similar (Table 1). The mean age of the early use group was 65.6 years, and $50 \%$ were male. Among them, seven patients $(58.3 \%)$ had a history of hypertension. The most common symptoms were fever (75\%), cough (50\%), sputum $(41.7 \%)$, dyspnea (41.7\%), and fatigue (41.7\%). Patients were assessed based on an ordinal scale; four patients $(33.3 \%)$ had a score of 2 (limit of activity but no $\left.\mathrm{O}_{2}\right)$; five $(41.7 \%)$ had a score of $3\left(\mathrm{O}_{2}\right.$ with nasal prong), and three $(25 \%)$ had a score of 5 (high flow nasal cannula). Baseline laboratory tests were similar between the two groups. The initial $\mathrm{PaO}_{2} / \mathrm{FiO}_{2}$ ratio in the early use group was 124.89 . The inflammatory markers were elevated; the mean levels of ferritin, ESR, and CRP were $804.22 \pm 601.11 \mathrm{ng} / \mathrm{mL}, 60.00 \pm 35.78$, and $10.33 \pm 8.95$, respectively.

The therapeutic options and timing differences of patients are shown in Table 2. Most patients used methylprednisolone, and only one patient used hydrocortisone. Corticosteroids were initiated within a median of $9.75 \pm$ 3.64 days of the onset of symptoms, 3.00 (2.00-7.00) days of the confirmation, and $3.33 \pm 3.45$ days after hospital admission. The initial dose of corticosteroid administered was $0.81 \quad(0.50-1.00) \quad \mathrm{mg} \quad \mathrm{kg}^{-1}$ day $^{-1}$ methylprednisolone, and patients were treated for $14.00 \pm 5.00$ days. The total dose administered was $521.6 \pm 246.38 \mathrm{mg}$ methylprednisolone.

Table 3 shows the comparison of laboratory findings before and after corticosteroid use. Significant changes in lymphocyte count, lactate dehydrogenase, and inflammatory markers (ferritin, CRP, and procalcitonin) were observed after corticosteroid administration in both groups. The $\mathrm{PaO}_{2} / \mathrm{FiO}_{2}$ ratio and $\mathrm{Ct}$ value improved in both groups. However, when comparing changes between the two groups, there was no significant difference in improvement (Fig. 1).
Table 1 Comparisons of baseline demographics and characteristics in patients with severe COVID-19

\begin{tabular}{|c|c|c|}
\hline Characteristics & $\begin{array}{l}\text { Early use group } \\
(n=12)\end{array}$ & $\begin{array}{l}\text { Late use group }(n= \\
\text { 10) }\end{array}$ \\
\hline Age (years) mean $\pm S D$ & $65.6 \pm 5.6$ & $74.6 \pm 4.6$ \\
\hline \multicolumn{3}{|l|}{ Sex, No. (\%) } \\
\hline Male & $6 / 12(50 \%)$ & $6 / 10(60 \%)$ \\
\hline \multicolumn{3}{|c|}{ Coexisting disease, No. (\%) } \\
\hline Hypertension & $7 / 12(58.3 \%)$ & $4 / 10(30 \%)$ \\
\hline Diabetes & $3 / 12(25 \%)$ & $3 / 10(30 \%)$ \\
\hline Malignant neoplasm & $2 / 12(16.7 \%)$ & $1 / 10(10 \%)$ \\
\hline \multicolumn{3}{|l|}{ Symptoms } \\
\hline Fever & $9 / 12(75 \%)$ & $7 / 10(70 \%)$ \\
\hline Cough & $6 / 12(50 \%)$ & $3 / 10(30 \%)$ \\
\hline Sputum & $5 / 12(41.7 \%)$ & $4 / 10(40 \%)$ \\
\hline Dyspnea & $5 / 12(41.7 \%)$ & $4 / 10(40 \%)$ \\
\hline Myalgia & $5 / 12(41.7 \%)$ & $2 / 10(20 \%)$ \\
\hline Fatigue & $5 / 12(41.7 \%)$ & $1 / 10(10 \%)$ \\
\hline Poor oral intake & 4/12 (33.3\%) & $1 / 10(10 \%)$ \\
\hline \multicolumn{3}{|c|}{ Initial score on ordinal scale } \\
\hline No limit of activity & 0 & 0 \\
\hline $\begin{array}{l}\text { Limit of activity but } \\
\text { no } \mathrm{O}_{2}\end{array}$ & 4/12 (33.3\%) & $4 / 10(40 \%)$ \\
\hline $\mathrm{O}_{2}$ with nasal prong & $5 / 12(41.7 \%)$ & $2 / 10(20 \%)$ \\
\hline $\mathrm{O}_{2}$ with facial mask & 0 & 0 \\
\hline $\begin{array}{l}\text { High flow nasal } \\
\text { cannula }\end{array}$ & $3 / 12(25 \%)$ & $3 / 10(30 \%)$ \\
\hline $\begin{array}{l}\text { Non-invasive } \\
\text { ventilation }\end{array}$ & 0 & 0 \\
\hline Invasive ventilation & 0 & 0 \\
\hline Baseline score missing & 0 & $1 / 10(10 \%)$ \\
\hline Initial $\mathrm{PaO} 2 / \mathrm{FiO}_{2}$ ratio & $124.89 \pm 42.60$ & $133.35 \pm 49.40$ \\
\hline
\end{tabular}

COVID-19, coronavirus disease 2019; SD, standard deviation Data are expressed as mean \pm SD or number (\%)

Table 4 shows the comparison of clinical outcomes between the two groups. The duration of hospital stay was shorter in the early use group than in the late use group ( $26.0 \pm 11.4$ vs. $53.9 \pm 23.0$ days, $P=0.033$ ). The time from corticosteroid use to discharge was 25.6 days in the early use group and 46.3 days in the late use group, but the difference was not significant $(P=0.096)$. We could not demonstrate a correlation between the time between diagnosis and corticosteroid use, and the duration of hospital stay $\left(\mathrm{R}^{2}=0.143, P=\right.$ 0.213) (Fig. 2). There was no significant difference in the overall mortality. None of the patients in either group suffered secondary bacterial infection or hyperglycemia.

\section{Discussion}

The COVID-19 pandemic has been worsening and spreading worldwide. Although many types of treatment, 
Table 2 Factors associated with therapeutic option in patients with severe COVID-19

\begin{tabular}{|c|c|c|c|}
\hline & Early use group $(n=12)$ & Late use group $(n=10)$ & $p$-value \\
\hline \multicolumn{4}{|l|}{ Combination therapy } \\
\hline Steroid & $7 / 12(58.3 \%)$ & $8 / 10(80.0 \%)$ & 0.162 \\
\hline Steroid + Convalescent plasma & $5 / 12(41.7 \%)$ & $1 / 10(10.0 \%)$ & \\
\hline Steroid + Remdesivir & 0 & $1 / 10(10.0 \%)$ & \\
\hline \multicolumn{4}{|l|}{ Steroid-related factor } \\
\hline Time from symptom to steroid use & $9.75 \pm 3.64$ & $15.70 \pm 6.00$ & 0.010 \\
\hline Time from diagnosis to steroid use & $3.00(2.00-7.00)$ & $12.5(11.00-14.25)$ & $<0.001$ \\
\hline Time from hospitalization to steroid use & $3.33 \pm 3.45$ & $10.00 \pm 4.83$ & 0.001 \\
\hline Initial dose ${ }^{a}, \mathrm{mg} / \mathrm{kg} /$ day & $0.81(0.50-1.00)$ & $1.00(0.76-.1 .00)$ & 0.456 \\
\hline Duration, days & $14.00 \pm 5.00$ & $18.50 \pm 14.76$ & 0.380 \\
\hline Total dose ${ }^{a}, \mathrm{mg}$ & $521.6 \pm 246.38$ & $667.50 \pm 606.76$ & 0.490 \\
\hline Score on ordinal scale at steroid start & & & 0.035 \\
\hline $\mathrm{O}_{2}$ with nasal prong & $1 / 8(12.5 \%)$ & 0 & \\
\hline High flow nasal cannula & $7 / 8(87.5 \%)$ & $2 / 5(40 \%)$ & \\
\hline Invasive ventilation & 0 & $3 / 5(60 \%)$ & \\
\hline
\end{tabular}

COVID-19, coronavirus disease 2019

Continuous variables were examined for normality by Kolmogorov-Smirnov test. Continuous variables with normal distribution are shown mean \pm standard deviation (SD). Group comparisons were performed using independent two-sample t-test. Continuous non-normal distribution variables are shown as the median interquartile range, and Mann-Whitney $U$ tests were used to compare the differences between groups. Categorical variables are shown as numbers (percentages). Chi-squared tests and Fisher's exact test were used to compare categorical data in different groups

${ }^{a}$ Dose of corticosteroid was calculated based on methylprednisolone

including chloroquine, hydroxychloroquine, lopinavir/ritonavir, azithromycin, intravenous immune globulin, and convalescent plasma transfusion, have been used in the early phase of COVID-19 pandemic, they have been proven to be ineffective and are no longer used. An antiviral agent like Remdesivir [11], as well as immunomodulatory agents such as Tocilizumab (IL-6 inhibitor) [25] and Baaricitinib (JAK inhibitor) [26], and monoclonal antibodies like Bamlanivimab [27], and Casirivimab/ imdevimab [28] can be used to treat patients with COVID-19. However, these types of medicine have been found to be less useful in critically ill patients with COVID-19, so additional treatment options are still needed for patients with severe COVID-19.

Corticosteroids have long been considered to be effective in patients with acute respiratory distress syndrome, septic shock, and possibly viral pneumonia [29]; but this is still controversial. An interim guidance document released on May 27, 2020 by the World Health Organization on clinical management of COVID-19 recommended against the routine use of systemic corticosteroids for the treatment of viral pneumonia. The Infectious Disease Society of America recommends the use of corticosteroids in the context of clinical trials for patients with acute respiratory distress syndrome [30]. However, adherence to this recommendation remains low, with many studies suggesting opposite results. Studies favoring the use of corticosteroids began with the RECOVERY trial, which demonstrated that intravenous dexamethasone (6 mg daily for 10 days) reduced 28-day mortality in hospitalized patients with COVID-19 requiring oxygen therapy or mechanical ventilation [11]. This landmark trial has been supported by another trial $[19,31,32]$ and meta-analysis [15, 17, 18, 33]. These studies provide evidence on the effectiveness of corticosteroid, suggest a safe treatment option for COVID-19, and have changed our clinical practice regarding patients with severe COVID-19.

The pathogenesis of severe COVID-19 still remains unclear, but it is believed to have two overlapping pathologic subsets, similar to other types of viral pneumonia. In the early stage of infection, as SARS-CoV-2 replicates, mild clinical manifestations such as fever, malaise, and cough are observed. In most of these cases, patients recover without therapeutic support; but in other cases, they progress to severe disease. This is a result of host systemic inflammation rather than direct viral-induced tissue damage. Since sepsis and other critical illnesses occur for approximately 10 days [3], the maladaptive host response to the viral infection starts during this period. For this reason, anti-inflammatory therapy, such as corticosteroids, is not recommended for early use. Many studies have shown that corticosteroids can prolong viral shedding and cause secondary infections [3436]. In our study, patients were divided into two groups based on the duration from diagnosis to corticosteroid use on a 10-day basis. Both groups showed increasing $\mathrm{Ct}$ values after corticosteroid use. Within each group, the 


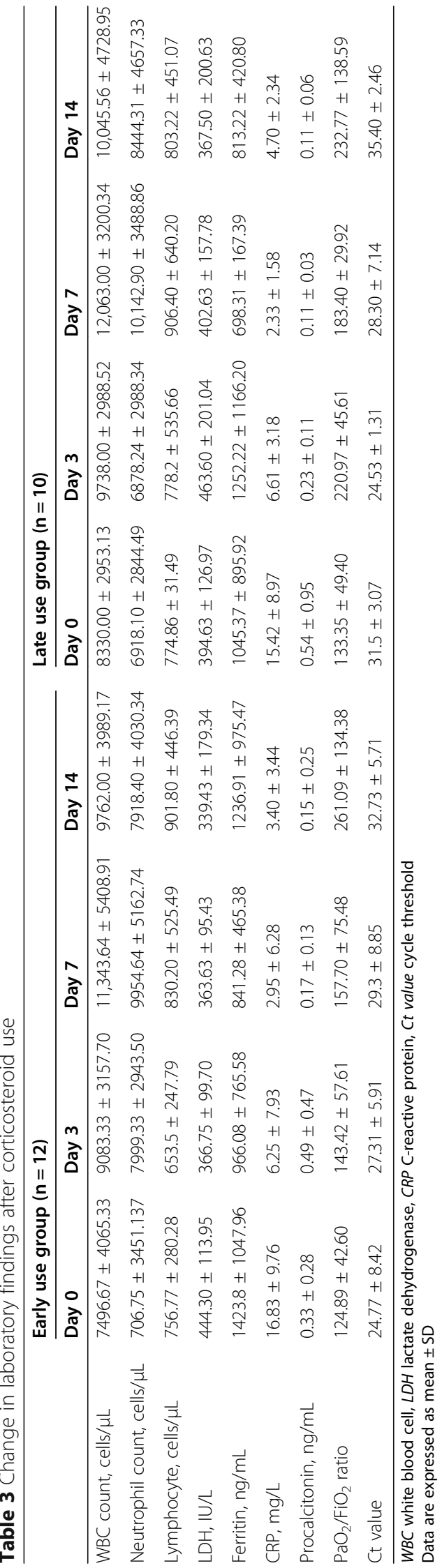




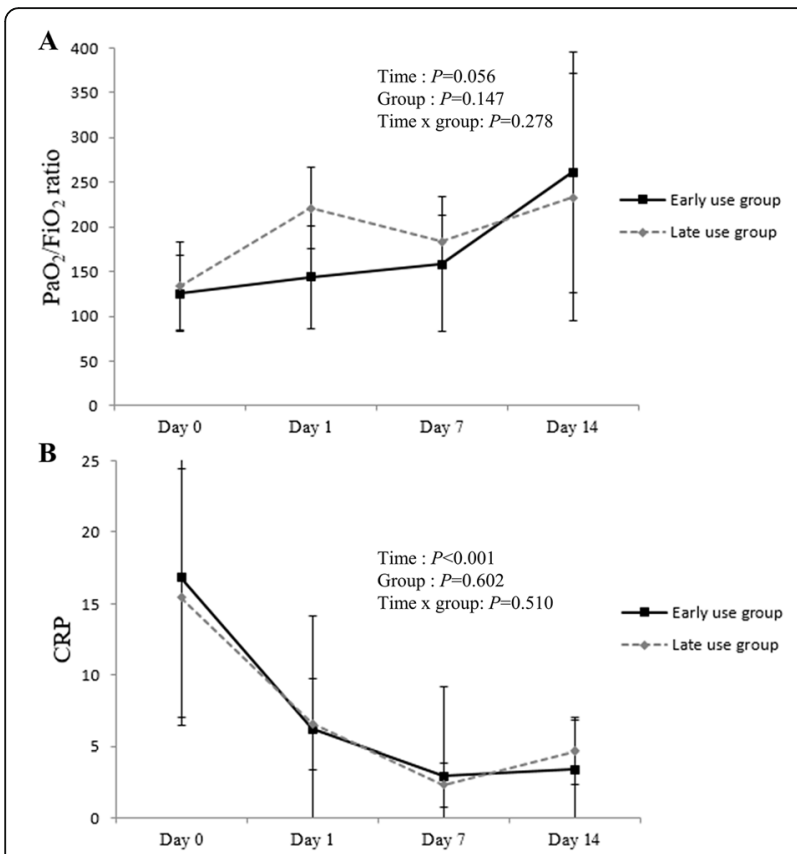

Fig. 1 Comparison of clinical response after corticosteroid use. A Changes in mean PaFiO2 ratio $\mathbf{B}$ Changes in mean CRP. Means were calculated and compared between groups at each time point using a linear mixed model. Error bars represent standard error. CRP,

C-reactive protein

increase was significant, but there was no difference between the two groups. Therefore, corticosteroid can be free from the stigma of inhibition of viral clearance for using corticosteroids in patients with severe COVID-1. Our findings were consistent with the results of a recent study [22].

As corticosteroids generally suppress the immune system response, there is a concern that they can accelerate secondary infections and cause many complications such as diabetes, psychosis, and avascular necrosis [36]. In our study, we assessed the patients' initial severity and response to corticosteroid using procalcitonin, CRP, and $\mathrm{LDH}$, as shown in Table 3, which were relatively wellstudied regarding the predictability of severity [7].
Patients with lymphopenia recovered, and inflammatory parameters such as ferritin, CRP, and procalcitonin also improved after corticosteroid use in both groups, although there was no difference between the two groups. Corticosteroid-related complications were not noted.

The mean length of hospital stay for COVID-19 patients varies from 4 to 11 days, and those with severe and life-threatening cases of COVID-19 remain hospitalized for longer periods [3,37]. In our study, the early use group stayed in the hospital for 26 days, whereas the late use group styed for 53.9 days. Early corticosteroid use within 10 days after diagnosis did not reduce mortality but reduced hospital stay compared to late corticosteroid use. Therefore, it is important to use corticosteroids in patients with severe COVID-19 at the most appropriate time.

Our study had several limitations. First, the sample size was small. It is important to note that the number of patients with severe COVID-19 in South Korea is relatively low compared to other countries around the world. For this reason, the sample size was limited, despite the participation of many tertiary hospitals in this study. To overcome this, we further analyzed clinical outcome and confirmed that it was meaningful (power of time from diagnosis to discharge, time from symptom to discharge, and lenth of hospital stay $=0.97,0.967$, and 0.997). The linear mixed model is exploratory, and further research is needed by increasing the sample size. Second, there was insufficient data on the clinical symptoms and missing laboratory findings. Third, since our study was performed retrospectively, some confounders could not be excluded. Both the dose and duration of corticosteroid use in the study varied for each patient. Fourth, the 10-day-based group was a relatively random request, and it should be further divided into subgroups in follow-up studies. Therefore, further large-scale studies in patients with severe COVID-19 are required. Fifth, the initial $\mathrm{Ct}$ values between the two groups were different. The difference in initial $\mathrm{Ct}$ values suggest that patients in the two groups may have different inflammation status, and this could have affected the

Table 4 Clinical outcomes in the early use and late use groups

\begin{tabular}{llll}
\hline & Early use group $(\boldsymbol{n}=\mathbf{1 2})$ & Late use group $(\boldsymbol{n}=\mathbf{1 0})$ & $\boldsymbol{p}$-value \\
\hline Time from diagnosis to discharge & $27.8 \pm 12.2$ & $57.4 \pm 22.5$ & 0.024 \\
Time from symptom to PCR-negative & $25.0(22.0-38.0)$ & $37.5 \pm(28.0-50.0)$ & 0.190 \\
Time from symptom to discharge & $32.4 \pm 13.1$ & $60.0 \pm 21.5$ & 0.030 \\
Time from corticosteroid use to discharge & $25.6 \pm 12.4$ & $46.3 \pm 22.7$ & 0.096 \\
Length of hospital stay & $26.0 \pm 11.4$ & $53.9 \pm 11.4$ & 0.033 \\
Overall mortality, No./Total (\%) & $1 / 12(8.3 \%)$ & $3 / 10(30 \%)$ & 0.293 \\
\hline
\end{tabular}

$P C R$ polymerase chain reaction

Continuous variables with normal distribution are shown as mean \pm SD. Group comparisons were performed using independent sample t-test. Continuous nonnormal distribution variables are shown as median interquartile range. and Mann-Whitney tests were used to compare the difference between groups 


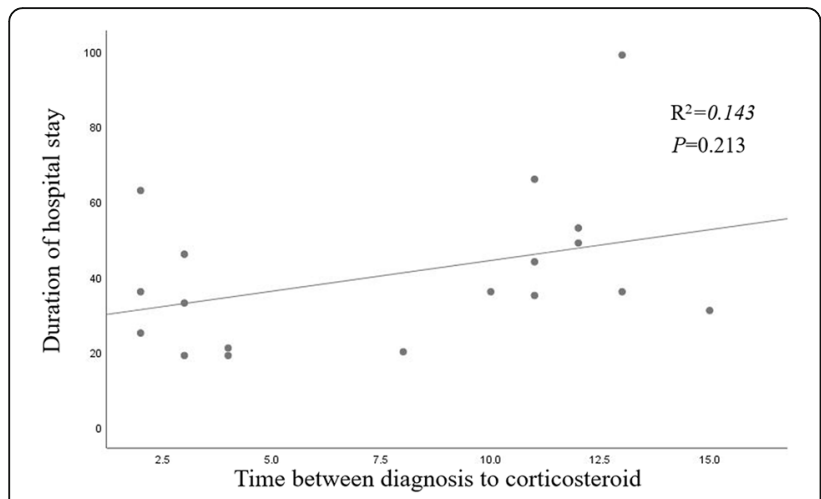

Fig. 2 Correlation between time of steroid use and duration of hospital stay in the early use group

outcomes in terms of steroids inhibiting inflammation. However, the lowest $\mathrm{Ct}$ value in the late use group was the same as that in the early use group. Sixth, most of the corticosteroids used in this study were methylprednisolone, rather than dexamethasone or hydrocortisone. Because the rationale for using dexamethasone is clear, many studies using other steroids have not been done. However recent studies have shown that methylprednisolone is not inferior to using dexamethasone [20].

Despite these limitations, our study provides valuable information on the clinical outcomes of using corticosteroids in patients with severe COVID-19. The results of this study supported the notion that corticosteroids can be a potential treatment option for severe COVID-19, and that it can be beneficial to use corticosteroids early within 10 days in severe COVID-19 patients.

\section{Conclusions}

In conclusion, corticosteroids can be one of the treatment options for patients with severe COVID-19, and early use of corticosteroids showed favorable clinical outcomes which are related to a reduction in the length of hospital stay.

\section{Abbreviations}

COVID-19: Coronavirus disease 2019; SARS-CoV-2: Severe acute respiratory syndrome coronavirus 2; CRP: C-reactive protein; ESR: Erythrocyte sedimentation rate; Ct: Cycle threshold; SD: Standard deviation

\section{Acknowledgements}

Not applicable.

\section{Authors' contributions}

Conceptualization: SJJ. Data curation: MHK. Formal analysis: YS. Investigation: YC. Methodology: YJB. Software: JHK. Validation: MYA, EJK, HC. Visualization: JB, YKK. Writing - original draft: JHH. Writing - review \& editing: SJJ, JYC, JSY. All authors have read and approved the final manuscript.

\section{Funding}

This study received no external funding.

\section{Availability of data and materials}

All data and material collected in the current study are available from the corresponding author upon reasonable request.

\section{Declarations}

Ethics approval and consent to participate

The study was approved by the Institutional Review Boards of Severance Hospital (Seoul, South Korea), and written informed consent was waived.

Consent for publication

Not applicable.

Competing interests

No competing interests to declare.

\section{Author details}

'Department of Internal Medicine, Severance Hospital, Yonsei University College of Medicine, 50-1 Yonsei-ro Seodaemun-gu, Seoul 03722, South Korea. ${ }^{2}$ Department of Internal Medicine, Seoul Medical Center, Seoul, South Korea. ${ }^{3}$ Department of Infectious Diseases, Ajou University School of Medicine, Suwon, South Korea. ${ }^{4}$ Department of Internal Medicine, Inha University School of Medicine, Incheon, South Korea. ${ }^{5}$ Department of Internal Medicine, Yonsei University Wonju College of Medicine, Wonju, South Korea. ${ }^{6}$ Department of Infectious Disease, National Health Insurance Service Ilsan Hospital, Goyang, South Korea.

Received: 27 October 2020 Accepted: 21 May 2021

Published online: 31 May 2021

\section{References}

1. Zhu N, Zhang D, Wang W, Li X, Yang B, Song J, et al. A novel coronavirus from patients with pneumonia in China, 2019. N Engl J Med. 2020;382(8): 727-33. https://doi.org/10.1056/NEJMoa2001017.

2. World Health Organization. Coronavirus disease (COVID-19). Weekly Epidemiological Update. World Health Organization. https://www.who.int/ docs/default-source/coronaviruse/situation-reports/20200831-weekly-epiupdate-3.pdf. Accessed September 162020.

3. Zhou F, Yu T, Du R, Fan G, Liu Y, Liu Z, et al. Clinical course and risk factors for mortality of adult inpatients with COVID-19 in Wuhan, China: a retrospective cohort study. Lancet. 2020;395(10229):1054-62. https://doi. org/10.1016/50140-6736(20)30566-3.

4. Kumar A, Arora A, Sharma P, Anikhindi SA, Bansal N, Singla V, et al. Is diabetes mellitus associated with mortality and severity of COVID-19? A meta-analysis. Diabetes Metab Syndr. 2020;14(4):535-45. https://doi.org/10.1 016/j.dsx.2020.04.044.

5. Wu Z, McGoogan JM. Characteristics of and important lessons from the coronavirus disease 2019 (COVID-19) outbreak in China: summary of a report of 72314 cases from the Chinese Center for Disease Control and Prevention. JAMA. 2020;323(13):1239-42. https://doi.org/10.1001/jama.2020.2 648.

6. Mehta P, McAuley DF, Brown M, Sanchez E, Tattersall RS, Manson JJ. COVID19: consider cytokine storm syndromes and immunosuppression. Lancet. 2020;395(10229):1033-4. https://doi.org/10.1016/S0140-6736(20)30628-0.

7. Hariyanto TI, Japar KV, Kwenandar F, Damay V, Siregar Jl, Lugito NPH, et al. Inflammatory and hematologic markers as predictors of severe outcomes in COVID-19 infection: a systematic review and meta-analysis. Am J Emerg Med. 2021;41:110-9. https://doi.org/10.1016/j.ajem.2020.12.076.

8. Siddiqi HK, Mehra MR. COVID-19 illness in native and immunosuppressed states: a clinical-therapeutic staging proposal. J Heart Lung Transplant. 2020; 39(5):405-7. https://doi.org/10.1016/j.healun.2020.03.012.

9. Sanders JM, Monogue ML, Jodlowski TZ, Cutrell JB. Pharmacologic treatments for coronavirus disease 2019 (COVID-19): a review. JAMA. 2020; 323(18):1824-36. https://doi.org/10.1001/jama.2020.6019.

10. Beigel JH, Tomashek KM, Dodd LE, Mehta AK, Zingman BS, Kalil AC, et al. Remdesivir for the treatment of Covid-19 - preliminary report. N Engl J Med. 2020;383(19):1813-26. https://doi.org/10.1056/NEJMoa2007764.

11. RECOVERY Collaborative Group; Horby P, Lim WS, Emberson JR, Mafham M, Bell JL, et al. Dexamethasone in hospitalized patients with Covid-19. N Engl J Med. 2021:384(8):693-704.

12. Sarkar S, Khanna P, Soni KD. Are the steroids a blanket solution for COVID19? A systematic review and meta-analysis. J Med Virol. 2021;93(3):1538-47. https://doi.org/10.1002/jmv.26483.

13. Singh AK, Majumdar S, Singh R, Misra A. Role of corticosteroid in the management of COVID-19: a systemic review and a Clinician's perspective. 
Diabetes Metab Syndr. 2020;14(5):971-8. https://doi.org/10.1016/j.dsx.2020. 06.054.

14. Rodríguez-Molinero A, Pérez-López C, Gálvez-Barrón C, Miñarro A, Rodríguez Gullello EA, Collado Pérez I, et al. Association between high-dose steroid therapy, respiratory function, and time to discharge in patients with COVID19: cohort study. Medicina Clínica (English Edition). 2021;156(1):7-12. https:// doi.org/10.1016/j.medcle.2020.08.001.

15. van Paassen J, Vos JS, Hoekstra EM, Neumann KMI, Boot PC, Arbous SM. Corticosteroid use in COVID-19 patients: a systematic review and metaanalysis on clinical outcomes. Crit Care. 2020;24(1):696

16. Yuan M, Xu X, Xia D, Tao Z, Yin W, Tan W, et al. Effects of corticosteroid treatment for non-severe COVID-19 pneumonia: a propensity score-based analysis. Shock. 2020;54(5):638-43. https://doi.org/10.1097/SHK. 0000000000001574 .

17. Lee KH, Yoon S, Jeong GH, Kim JY, Han YJ, Hong SH, et al. Efficacy of Corticosteroids in Patients with SARS, MERS and COVID-19: A Systematic Review and Meta-Analysis. J Clin Med. 2020:9(8).

18. Group TWREAfC-TW. Association between Administration of Systemic Corticosteroids and Mortality among Critically ill Patients with COVID-19: a meta-analysis. JAMA. 2020;324(13):1330-41.

19. Angus DC, Derde L, Al-Beidh F, Annane D, Arabi Y, Beane A, et al. Effect of hydrocortisone on mortality and organ support in patients with severe COVID-19: the REMAP-CAP COVID-19 corticosteroid domain randomized clinical trial. JAMA. 2020;324(13):1317-29. https://doi.org/10.1001/jama.202 0.17022.

20. Ranjbar K, Moghadami M, Mirahmadizadeh A, Fallahi MJ, Khaloo V, Shahriarirad R, et al. Methylprednisolone or dexamethasone, which one is superior corticosteroid in the treatment of hospitalized COVID-19 patients: a triple-blinded randomized controlled trial. BMC Infect Dis. 2021;21(1):337. https://doi.org/10.1186/s12879-021-06045-3.

21. Mattos-Silva P, Felix NS, Silva PL, Robba C, Battaglini D, Pelosi P, et al. Pros and cons of corticosteroid therapy for COVID-19 patients. Respir Physiol Neurobiol. 2020;280:103492. https://doi.org/10.1016/j.resp.2020.103492.

22. Spagnuolo V, Guffanti M, Galli L, Poli A, Querini PR, Ripa M, et al. Viral clearance after early corticosteroid treatment in patients with moderate or severe covid-19. Sci Rep. 2020;10(1):21291. https://doi.org/10.1038/s41598-02 0-78039-1.

23. Naser Moghadasi A, Shabany M, Heidari H, Eskandarieh S. Can pulse steroid therapy increase the risk of infection by COVID-19 in patients with multiple sclerosis? Clin Neurol Neurosurg. 2021;203:106563. https://doi.org/10.1016/j. clineuro.2021.106563.

24. Villar J, Confalonieri M, Pastores SM, Meduri GU. Rationale for Prolonged Corticosteroid Treatment in the Acute Respiratory Distress Syndrome Caused by Coronavirus Disease 2019. Crit Care Explor. 2020;2(4):e0111.

25. Salama C, Han J, Yau L, Reiss WG, Kramer B, Neidhart JD, et al. Tocilizumab in patients hospitalized with Covid-19 pneumonia. N Engl J Med. 2020; 384(1):20-30. https://doi.org/10.1056/NEJMoa2030340.

26. Kalil AC, Patterson TF, Mehta AK, Tomashek KM, Wolfe CR, Ghazaryan V, et al. Baricitinib plus Remdesivir for hospitalized adults with Covid-19. N Engl J Med. 2020;384(9):795-807. https://doi.org/10.1056/NEJMoa2031994.

27. Chen P, Nirula A, Heller B, Gottlieb RL, Boscia J, Morris J, et al. SARS-CoV-2 neutralizing antibody LY-CoV555 in outpatients with Covid-19. N Engl J Med. 2020;384(3):229-37. https://doi.org/10.1056/NEJMoa2029849.

28. Weinreich DM, Sivapalasingam S, Norton T, Ali S, Gao H, Bhore R, et al. REGN-COV2, a neutralizing antibody cocktail, in outpatients with Covid-19. N Engl J Med. 2020;384(3):238-51. https://doi.org/10.1056/NEJMoa2035002.

29. Ashbaugh DG, Bigelow DB, Petty TL, Levine BE. Acute respiratory distress in adults. Lancet. 1967;2(7511):319-23. https://doi.org/10.1016/s0140-673 6(67)90168-7.

30. Bhimraj A, Morgan RL, Shumaker AH, Lavergne V, Baden L, Cheng VC, et al. Infectious Diseases Society of America guidelines on the treatment and Management of Patients with COVID-19. Clin Infect Dis. 2020. https://doi. org/10.1093/cid/ciaa478.

31. Tomazini BM, Maia IS, Cavalcanti AB, Berwanger O, Rosa RG, Veiga VC, et al. Effect of dexamethasone on days alive and ventilator-free in patients with moderate or severe acute respiratory distress syndrome and COVID-19: the CoDEX randomized clinical trial. JAMA. 2020;324(13):1307-16. https://doi. org/10.1001/jama.2020.17021.

32. Dequin PF, Heming N, Meziani F, Plantefève G, Voiriot G, Badié J, et al. Effect of hydrocortisone on 21-day mortality or respiratory support amons critically ill patients with COVID-19: a randomized clinical trial. JAMA. 2020; 324(13):1298-306. https://doi.org/10.1001/jama.2020.16761.

33. Siemieniuk RA, Bartoszko JJ, Ge L, Zeraatkar D, Izcovich A, Pardo-Hernandez $H$, et al. Drug treatments for covid-19: living systematic review and network meta-analysis. BMJ. 2020;370:m2980.

34. Arabi YM, Mandourah Y, Al-Hameed F, Sindi AA, Almekhlafi GA, Hussein MA, et al. Corticosteroid therapy for critically ill patients with Middle East respiratory syndrome. Am J Respir Crit Care Med. 2018;197(6):757-67. https://doi.org/10.1164/rccm.201706-11720C.

35. Rodrigo C, Leonardi-Bee J, Nguyen-Van-Tam J, Lim WS. Corticosteroids as adjunctive therapy in the treatment of influenza. Cochrane Database Syst Rev. 2016;3:Cd010406.

36. Russell CD, Millar JE, Baillie JK. Clinical evidence does not support corticosteroid treatment for 2019-nCoV lung injury. Lancet. 2020;395(10223): 473-5. https://doi.org/10.1016/S0140-6736(20)30317-2.

37. Richardson S, Hirsch JS, Narasimhan M, Crawford JM, McGinn T, Davidson $\mathrm{KW}$, et al. Presenting characteristics, comorbidities, and outcomes among 5700 patients hospitalized with COVID-19 in the new York City area. JAMA. 2020;323(20):2052-9. https://doi.org/10.1001/jama.2020.6775.

\section{Publisher's Note}

Springer Nature remains neutral with regard to jurisdictional claims in published maps and institutional affiliations.
Ready to submit your research? Choose BMC and benefit from:

- fast, convenient online submission

- thorough peer review by experienced researchers in your field

- rapid publication on acceptance

- support for research data, including large and complex data types

- gold Open Access which fosters wider collaboration and increased citations

- maximum visibility for your research: over $100 \mathrm{M}$ website views per year

At BMC, research is always in progress.

Learn more biomedcentral.com/submissions 